\title{
Behavioral and Physiological Responses to Computers in the Ultimatum Game
}

\author{
Aleksandra Swiderska, Department of Psychology, Warsaw University, Warsaw, Poland \\ Eva G. Krumhuber, Department of Experimental Psychology, University College London, London, UK \\ Arvid Kappas, Department of Psychology and Methods, Jacobs University Bremen, Bremen, Germany
}

\begin{abstract}
This article describes how studies in the area of decision-making suggest clear differences in behavioral responses to humans versus computers. The current objective was to investigate decision-making in an economic game played only with computer partners. In Experiment 1, participants were engaged in the ultimatum game with computer agents and regular computers while their physiological responses were recorded. In Experiment 2, an identical setup of the game was used, but the ethnicity of the computer agents was manipulated. As expected, almost all equitable monetary splits offered by the computer were accepted. The acceptance rates gradually decreased when the splits became less fair. Although the obtained behavioral pattern implied a reaction to violation of the rule of fairness by the computer in the game, no evidence was found for participants' corresponding emotional involvement. The findings contribute to the body of research on human-computer interaction and suggest that social effects of computers can be attenuated.
\end{abstract}

\section{KEYWORDS}

Agency, Anthropomorphism, Decision-making, Ethopoeia, Proposer, Psychophysiology, Threshold Model of Social Influence,

\section{INTRODUCTION}

Humans have a natural tendency to perceive non-human and non-living entities in terms of human qualities - they readily attribute the power to act or to intentionally behave in a certain way to animals, natural forces, gods, and technological gadgets, and thus create human-like agents in the surrounding environment (Waytz, Epley, \& Cacioppo, 2010). One of the most scrutinized inanimate social actors is the computer. In this context, experiments that investigated the mechanisms of human-human interactions (HHI) were systematically adapted to the study of human-computer interactions (HCI). Substituting participants' interaction partner with a regular computer, it was shown that people adhere to politeness norms when they respond to computers, apply gender stereotypes, and take part in mutual self-disclosure (e.g, Nass, Moon, \& Carney, 1999; Nass, Moon, \& Green, 1997). The term "media equation" was coined to refer to these effects (Reeves \& Nass, 1996). Invoking the ethopoeia approach, they were explained to occur due to the mindlessness of the computer users who unconsciously implement accessible behavioral scripts suited for social exchange in settings that involve computers, even though social cues in such settings are sometimes minimal (Nass \& Moon, 2000).

Computers with anthropomorphic characters as interfaces have been demonstrated to instantly evoke reactions normally reserved for humans (Yee, Bailenson, \& Rickertsen, 2007). However, it is especially the plausibility of the characters' behavior that produces enough social cues to engender 
interpersonal dynamics (Tinwell, Grimshaw, Nabi, \& Williams, 2011). Behavioral realism and agency are two crucial factors responsible for the meaningfulness of HCI within the Threshold Model of Social Influence, an alternative to the ethopoeia approach (Blascovich et al., 2002). Behavioral realism denotes the extent to which the computer-generated characters act in a manner consistent with the user's expectations shaped throughout socialization, so mainly in everyday face-to-face interactions. It is even thought to be more essential than anthropomorphic appearance itself, which primarily serves to aid perception of given behaviors. Agency refers to whether artificial characters are perceived to accurately depict real people in real time.

How agency afforded by avatars (virtual personifications of the users operating in real time) and agents (virtual characters driven by a computer algorithm) influences people's responses in HCI remains unclear. Ethopoeia presumes that if avatars and agents exhibit enough social cues, they will elicit comparable social responses. This is parallel to how people would be expected to respond to regular computers, as demonstrated by research described earlier. Conversely, the Threshold Model of Social Influence predicts that since avatars represent real humans, their perceived agency is always greater. Hence, their social impact should be more pronounced in comparison to the agents. An interesting line of research that accommodated the versatile comparison of reactions to avatars and agents on the one hand and to humans and regular computers on the other was founded on a simple social decision-making paradigm frequently used in psychological experiments - the ultimatum game.

Typically, the ultimatum game engages two players, called the proposer and the responder. They have an amount of money to split between themselves. The proposer offers a certain amount to the responder and the responder's task is to either accept or reject it. If the offer is accepted, the money is distributed as determined by the proposer. If it is rejected, neither of the players gets the money. From the standard economic decision-making point of view, the proposer should offer the smallest possible amount and the responder should always accept it. In such a scenario, the players would take the only rational course of action - they would make decisions to boost their monetary gains (Becker, 2013). Nevertheless, it appears that proposers are inclined to split the money fairly and offer respondents approximately $50 \%$ of the amount at their disposal. Respondents frequently refuse lower offers and the rejection rates grow as the offers become less fair (Nowak, Page, \& Sigmund, 2000).

Unfair offers elicit anger and disgust in the respondents - emotions that arise in reaction to the perceived violations of social rules (e.g., Chapman, Kim, Susskind, \& Anderson, 2009). Rejection of the unfair offer is the means to punish the proposer for the social transgression and people tend to choose punishment even though it is paired with lack of financial gains for them as well (Fehr \& Gächter, 2002). Emotional components of decisions concerning unjust offers have been tackled further in studies that incorporated physiological measurements. Elevated electrodermal response (activity of sweat glands in the skin) may indicate emotional arousal and personal implication, and accompanies both reception and refusal of unfair offers (van't Wout, Kahn, Sanfey, \& Aleman, 2006). Activation of facial muscles at the site of Corrugator Supercilii (the muscle responsible for drawing the eyebrows to the middle and downward) has been linked to expressions of negative affect (visible as frowning), and together with the activation at other muscle sites has been associated respectively with anger (Cannon, Schnall, \& White, 2011) and disgust (Krumhuber, Tsankova, \& Kappas, 2016).

Notably, the full-fledged behavioral and emotional reactions take place particularly when people believe to play the game against another person. Unfair splits generated by a computer are accepted more willingly (Sanfey, Rilling, Aronson, Nystrom, \& Cohen, 2003). Ethopoeia effects in tasks that directly compare responses to computers with responses to humans are thereby attenuated - the overall magnitude of socio-affective reactions to computers diminishes. In an iteration of a decision-making dilemma with avatars and agents, the patterns of participants' behavioral responses were analogous to the responses to humans and regular computers found in prior research (de Melo, Gratch, \& Carnevale, 2013). This was interpreted as evidence in support of the importance of the agency component in HCI. However, the responses to avatars seemed to be addressed to the individuals behind them and responses to agents were really directed at an object. What would happen if human partners were removed from this equation? 


\section{OVERVIEW OF THE PRESENT RESEARCH}

The overarching aim of the current research was to examine behavioral and emotional responses in the ultimatum game played exclusively with computer proposers. There were two types of computer proposers that varied with regard to the degree of their anthropomorphic appearance. Specifically, the proposers were represented either by photos of artificially-looking faces and labeled as "agents" (highly anthropomorphic appearance) or by photos of a regular computer (non-anthropomorphic appearance). Involvement of other people in the ultimatum game was not implied; in fact, all of the offers were delivered by the same software. Research participants were assigned the role of the responder in the game.

Based on ethopoeia and on the Threshold Model of Social Influence, two divergent hypotheses pertaining to the behavioral responses in the game were formulated. First, as asserted by ethopoeia, participants were expected to respond in an entirely social manner to both types of the proposers since both computer agents and regular computers engaged them in the same social task and thereby contributed social cues. Unfair offers should appear as violation of social norms and consequently, both types of proposers should be alike punished by the responders with a rejection. However, it is worth emphasizing that anthropomorphic appearance of the agents actually provided more social cues than non-anthropomorphic appearance of a regular computer. Hence, responses to the former should be more social. Second, according to the Threshold Model of Social Influence, participants' social responses might be overall undermined because the agency of both types of the proposers was low (that is, none of them represented a real human being). Participants should be thus ready to accept unfair offers to maximize their own financial gains. Anthropomorphic appearance need not play a role as it is behavioral realism that produces the most salient social cues.

Physiological measures could be useful to further determine the nature of responses to the proposers. In line with previous findings, unfair offers from the computer agents were expected to be associated with increased activity of the Corrugator Supercilii and Levator Labii facial muscles (associated with expressions of anger and disgust) as well as with heightened skin conductance responses (SCR), which reflects more pronounced emotional engagement in the game and indicates a more social response to the agents in comparison to a regular computer. This would suggest that agency is not crucial for people to accept objects as legitimate social partners. Alternatively, if the agents were treated similarly to the computer, no changes in the activity of facial muscles and skin responses would occur after receiving unfair offers from the two types of proposers. This in turn would support the claim that entities of low agency are not recognized as proper social partners in an interaction.

The present setting, in which research participants played with multiple agents and one regular computer, corresponded to the earlier setups of the game employed in various studies, played with different humans and a single computer (Sanfey et al., 2003). It has been thereby established that reactions to unfair offers from humans, but not from the computer, were characterized by elevated electrodermal activation (van't Wout et al., 2006). Nevertheless, with a new human proposer in each round of the game and repetitive presentation of the same computer, previous research might have demonstrated an evaluative response to novelty, as this physiological measure is linked to it as well (see Bradley, Lang, \& Cuthbert, 1993). In order to address this probable shortcoming, an independent group of participants was engaged in a version of the ultimatum game played with multiple agents and multiple regular computers.

\section{EXPERIMENT 1}

The main purpose of the first experiment was to compare participants' behavioral and emotional responses to computer agents versus a regular computer in the ultimatum game. Additionally, another group of participants played the ultimatum game with computer agents and many regular computers. 


\section{Method}

Participants. 52 students (16 men), ranging in age from 18 to 25 years $(M=19.79, S D=1.26)$, at Jacobs University Bremen, Germany, participated in this study on a voluntary basis. They were recruited via e-mail and received $10 \%$ of the amount earned in the ultimatum game and a partial course credit as compensation. All participants were Caucasian and proficient English language users. Data of four participants were excluded from the analyses (one due to computer malfunction, three reported extensive knowledge of the ultimatum game in the debriefing session). The final sample comprised 48 participants.

Materials. Images of the proposers depicted 10 faces of Caucasian males obtained from the Center for Vital Longevity Face Database (Minear \& Park, 2004) and 11 computers, 10 of which were retrieved from the Internet and one was a photograph of a laboratory computer (see Figure 1). The faces were modified in Photoshop (CS3-ME, Adobe Systems Inc., 2007) to render them artificial (see Krumhuber, Swiderska, Tsankova, Kamble, \& Kappas, 2015). The images of faces and of the laboratory computer measured 473 x 586 pixels and were displayed vertically. The rest of the images of computers included monitors and other pieces of equipment (e.g., keyboards, mice), measured 660 x 586 pixels, and were displayed horizontally.

Procedure. Participants played 20 rounds of the ultimatum game, always in the role of the responder. In 10 rounds, the proposers were computer agents, represented by 10 pictures of artificial faces. In another 10 rounds, the proposer was a regular computer, represented by a single picture of a laboratory computer in one version of the game, or by 10 pictures of different computers in the additional setup. The versions differed only with respect to whether the proposer in the computer rounds was symbolized by always the same computer or by a different computer in every trial.

Computer and agent rounds were presented randomly. Each time, the amount of $10 €$ was divided. In each 10 rounds of the game, the proposers' offers were fair three times (5/5), and unfair 7 times (once $6 / 4$, three times $7 / 3$, twice $8 / 2$, once $9 / 1$ ). The rounds begun with a fixation point presented for

Figure 1. Examples of stimuli used as visual representations of the two types of proposers in Experiment 1: A facial image representing one of the computer "agents" and a regular computer

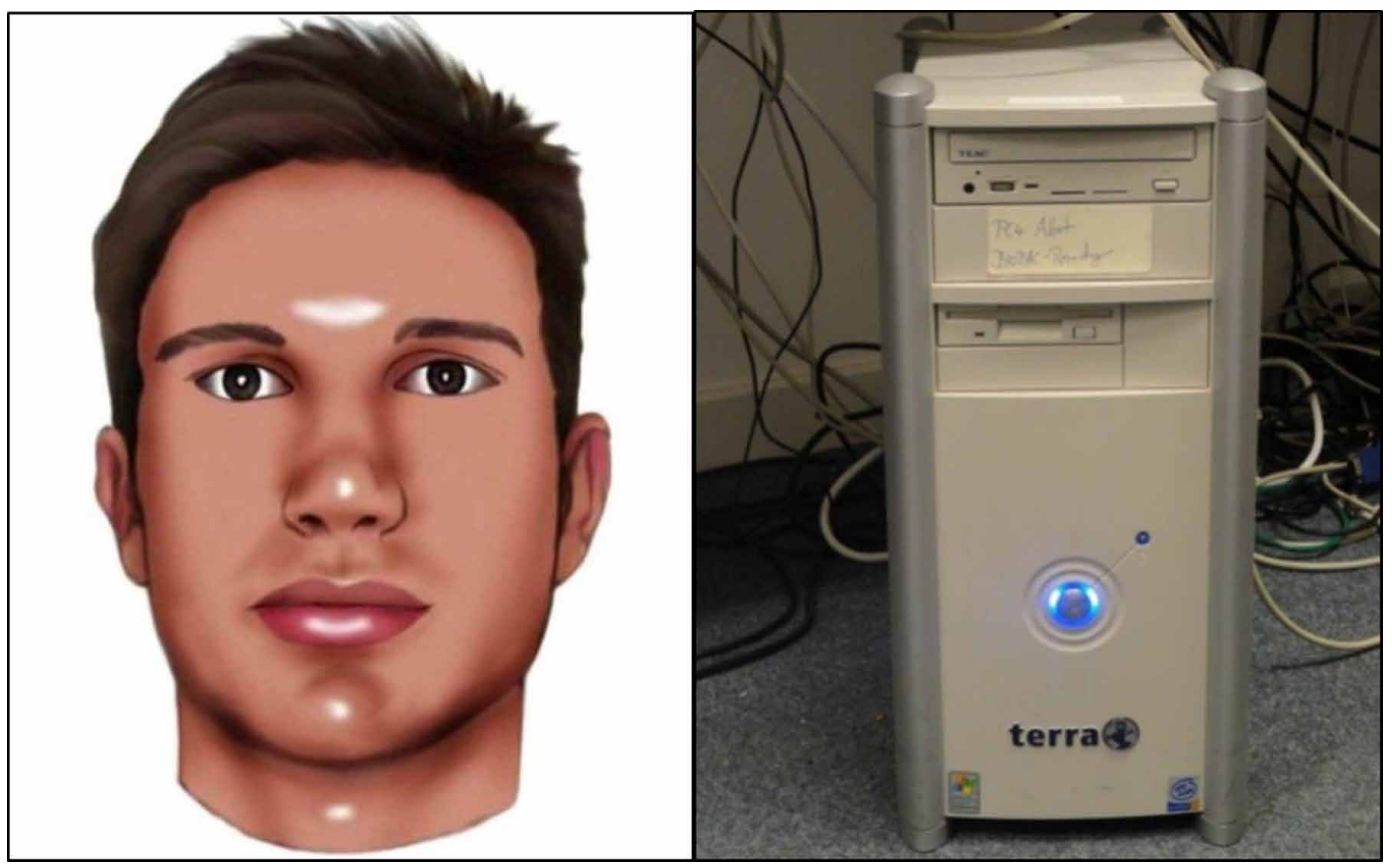


a varying interval of 3,6, or 9 seconds. Next, a picture of a proposer was displayed for 6 seconds, followed by an offer, displayed for 6 seconds as well, and lastly, a decision phase with no time limit. Participants' task was to either accept or reject the offers (see Figure 2).

\section{Apparatus and Physiological Recordings}

Participants were tested individually. They were seated in a reclining chair in a dimly lit soundabsorbent booth in front of a computer monitor, on which the experimental task was delivered by MediaLab software (V. 2010, Empirisoft Co., NYC, USA). Activity of facial muscles was recorded with three pairs of $11 \mathrm{~mm} \mathrm{Ag} / \mathrm{AgCl}$ (DM-Davis) miniature surface electrodes attached at the sites of Corrugator Supercili (associated with expressions of negative affect, e.g., frowning in anger), Levator Labii (associated with the expression of disgust), and additionally, Zygomaticus Major (as the activity of this muscle is associated with the expression of positive affect - smiling, it was measured here for the purpose of comparison with negative affect measures). One $20 \mathrm{~mm} \mathrm{Ag} / \mathrm{AgCl}$ electrode served as a ground reference. The placement of the electrodes adhered to the guidelines by Fridlund and Cacioppo (1986). Electrodermal activity was recorded with a pair of $8 \mathrm{~mm} \mathrm{Ag} / \mathrm{AgCl}$ electrodes attached to the distal phalanges of the index and middle finger of the non-dominant hand, as recommended by Boucsein and colleagues (2012). Data were acquired via MPR-150 BIOPAC system with three EMG-modules and one GSR-module, working with AcqKnowledge (V. 4.1; BIOPAC Systems Inc.) software, and filtered through a $50 \mathrm{~Hz}$ notch filter to reduce electrical noise.

Figure 2. Schematic representation of a single round of the ultimatum game in Experiment 1

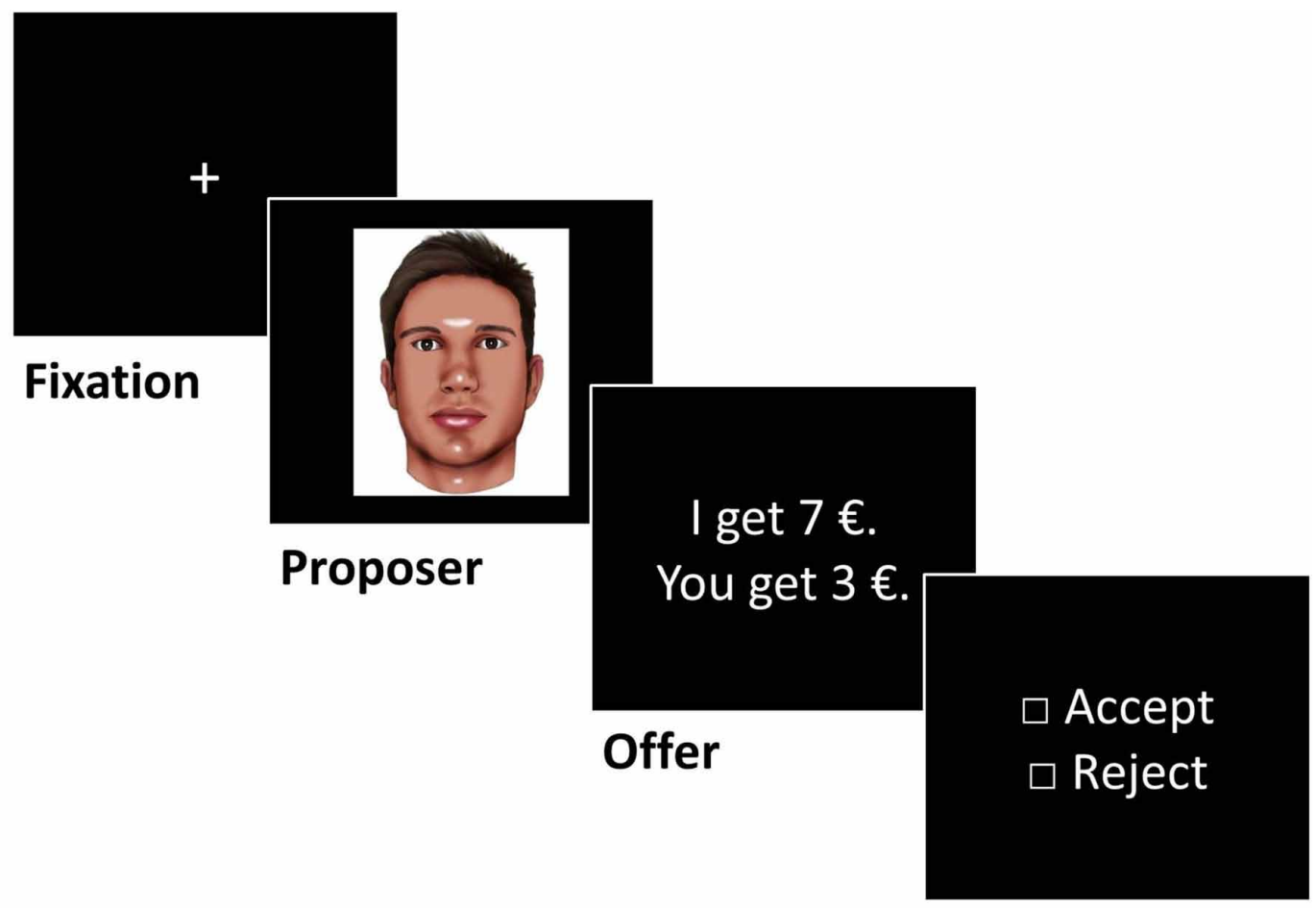

Decision 


\section{Results}

Behavioral responses. Percentages of accepted offers coming from the agents and the regular computer are shown in Figure 3. To test whether the acceptance rates differed depending on the type of the proposer and the type of the offer, a repeated-measures analysis of variance (ANOVA) was conducted with Proposer (Agents, Single Computer) and Offer (5/5, 6/4, 7/3, 8/2, 9/1) as within-subjects factors. The main effect of Proposer was significant, $F(1,23)=7.32, p=.013, \eta_{p}{ }^{2}=.24$. The main effect of Offer was also significant, $F(4,20)=27.73, p<.001, \eta_{p}{ }^{2}=.85$. However, the interaction between Proposer and Offer did not reach significance $(p>.05)$.

Pairwise comparisons revealed that participants were more likely to accept offers from the computer than the agents ( $M=.62$ vs. $M=.52$, respectively). Furthermore, acceptance rates decreased with lower offers, with significant differences occurring between offers $7 / 3,8 / 2$, and $9 / 1$ ( $p s<.05$ ) and between the fair and least unfair offers $(5 / 5$ and 6/6) and the other three types of unfair offers $(p s<.05)$.

For the version of the ultimatum game played with agents and multiple computers, a repeatedmeasures ANOVA with Proposer (Agents, Different Computers) and Offer (5/5, 6/4, 7/3, 8/2, 9/1) as within-subjects factors was conducted. The main effect of Proposer and the interaction between Proposer and Offer turned out to be non-significant $(p>.05)$. The main effect of Offer was again significant, $F(1,23)=27.48, p<.001, \eta_{p}^{2}=.85$, showing that the acceptance rates significantly differed between the fair and least unfair offers and other unfair offers $(p s<.05)$.

Physiological responses. The activities of Corrugator Supercilii, Levator Labii, and Zygomaticus Major as well as Skin Conductance Responses (SCR) were calculated separately for the two types of events in the ultimatum game: a) when the offers were made by the computer agents or regular computer, b) when the participant made the accept/reject decision. ANOVAs were conducted on four

Figure 3. Percentages of accepted offers in the ultimatum game played with 10 different agents and a single computer in Experiment 1

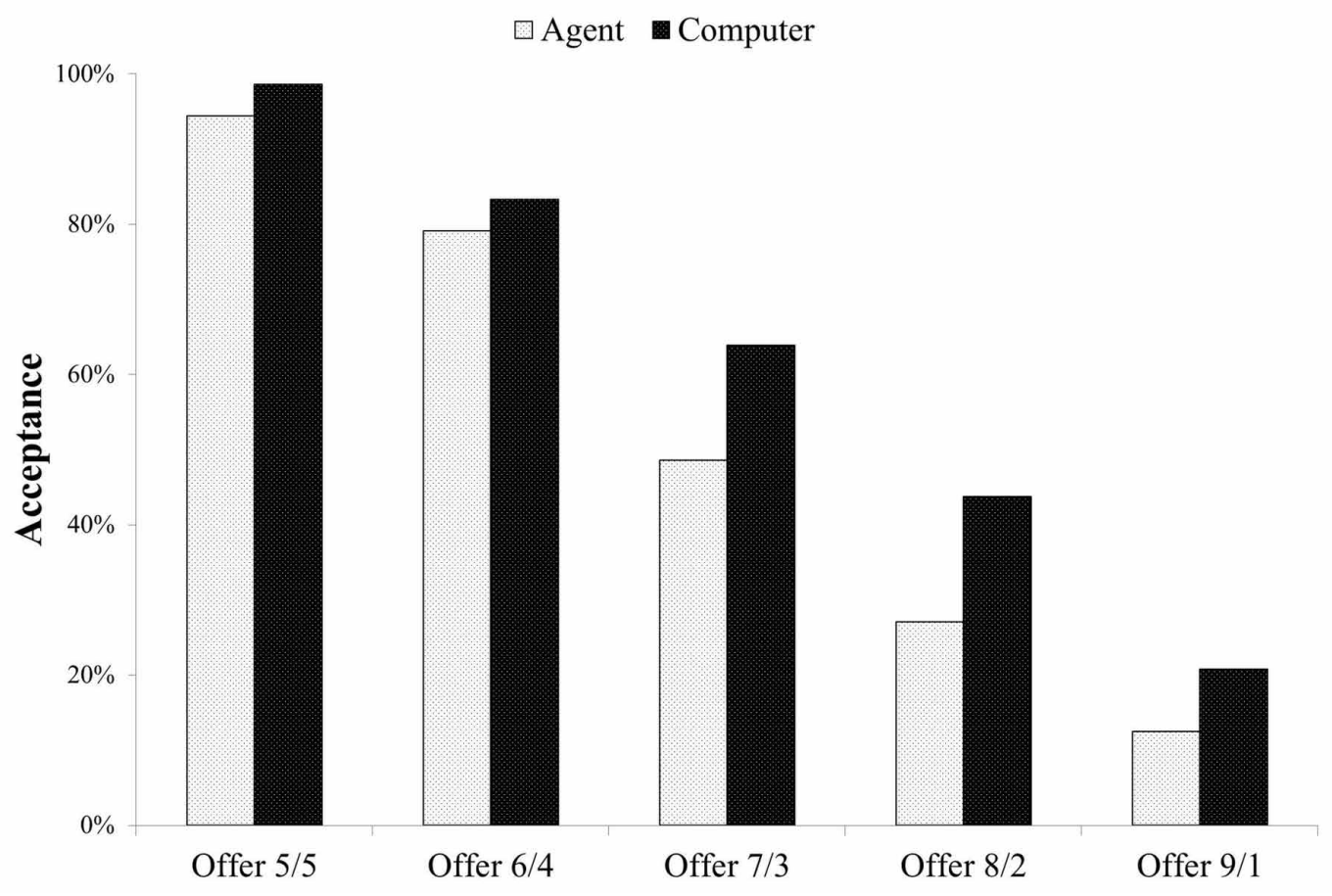


measures (activities of Corrugator Supercilii, Levator Labii, Zygomaticus Major, and SCR) for each of the 5 types of offers.

Results revealed significant differences in the context of the game played with agents versus a single computer. The main effect of Proposer was significant for Levator during presentation of Offer $6 / 4, F(1,23)=5.43, p=.029, \eta_{p}^{2}=.19$, and Offer $9 / 1, F(1,23)=6.86, p=.015, \eta_{p}^{2}=.23$. Specifically, activity of the Levator muscle (involved in disgust expressions) was higher when Offer $6 / 4$ came from the computer than the agents ( $M=.63$ vs. $M=.31$, respectively). The reverse was true for Offer $9 / 1$ ( $M=.11$ vs. $M=.40$; see Figure 4A). For Zygomaticus, the main effect of Proposer was significant again for Offer 6/4, $F(1,23)=4.48, p=.045, \eta_{p}^{2}=.16$, and Offer $7 / 3, F(1,23)=5.80, p$ $=.024, \eta_{p}{ }^{2}=.20$. Activity of Zygomaticus (involved in smiling) was higher when both Offer $6 / 4$ and Offer $7 / 3$ came from the computer than when it came from the agents $(M=.09$ vs. $M=-.10$ and $M$ $=.05$ vs. $M=-.10$; see Figure 4B). No significant results emerged during presentation of offers in the setup of the game played with agents versus multiple computers.

Considering physiological activity during the accept/reject decision phase of the game played with agents and a single computer, the only significant effect occurred for Offer $8 / 2, F(1,14)=6.87$, $p=.02, \eta_{p}^{2}=.33$, whereby SCR was higher in reaction to the agents than the computer $(M=.33$ vs. $M=-1.08$, respectively; see Figure 4C). In the case of the game played with agents and multiple computers, a significant effect occurred for Offer $6 / 4, F(1,20)=5.67, p=.027, \eta_{p}^{2}=.22$, when the activity of Zygomaticus was greater while responding to the offer from agents than computers $(M=$ -.12 vs. $M=-.32$ ). This singular result did not allow for drawing any firm conclusions and will not be discussed any further.

\section{Discussion}

In line with previous research that employed the ultimatum game, almost all fair offers were accepted. As the offers became less fair, the acceptance rates decreased for both the offers generated by the agents and the regular computer. The unfair offers made by the agents were accepted less often compared to the unfair offers from the regular computer. Therefore, on the behavioral level, participants seemed to differentiate between the two types of the proposers. Analyses of data obtained from the recordings of participants' physiological activity yielded highly inconsistent results, which did not allow us to ascertain the pattern of physiological changes dependent on the type of the proposer or the offer. In the additional setup of the ultimatum game played with agents and multiple computers, the behavioral differences depending on the type of the proposer vanished, suggesting that certain outcomes of the game might be due to a clear contrast between pondering offers from distinct proposers and repetitively from the same proposer.

Group membership is another factor shown to exert complex influence on the process of economic decision making. For example, when people can choose how to distribute the available resources, they divide them fairly between in-group and out-group, but when they are confronted with predetermined allotments, they favor the in-group (Mullen, Brown, \& Smith, 1992). When the decisions entail personal costs, as in the ultimatum game, people become less equitable and less rational (Kubota, Li, Bar-David, Banaji, \& Phelps, 2013). That is, at the expense of prospective earnings, they generally reject unfair offers and further discriminate based on race of the proposers, being more prone to reject offers from Blacks compared to Whites (Kubota et al., 2013). In Experiment 1, all participants were Caucasian and they were exposed to computer agents symbolized by Caucasian faces. The faces were thus presumed to function as a representation of participants' in-group. Although compared to the regular computers, unfair splits proposed by the agents were then dismissed more frequently, this effect warrants further scrutiny. In the following Experiment 2, the Caucasian faces were replaced by South Asian faces, which were to represent an out-group to participants drawn again from Caucasian students. The experiment's objective was to test whether such manipulation would strengthen participants' reactions to the agents and increase the rates of rejections of different unfair offers, parallel to what could be predicted for the ultimatum game played with human out-group members. 
Figure 4. Mean difference scores of Levator Labii (A) and Zygomaticus Major (B) muscles' activities, and SCR (C) to the presentation of the offers and response phases of the ultimatum game played with the agents and a single computer in Experiment 1 . The difference scores were calculated relative to 150 -second baseline preceding the game. Error bars denote $+S E$. The marked differences are significant at ${ }^{*} \mathrm{p}<.05$

A

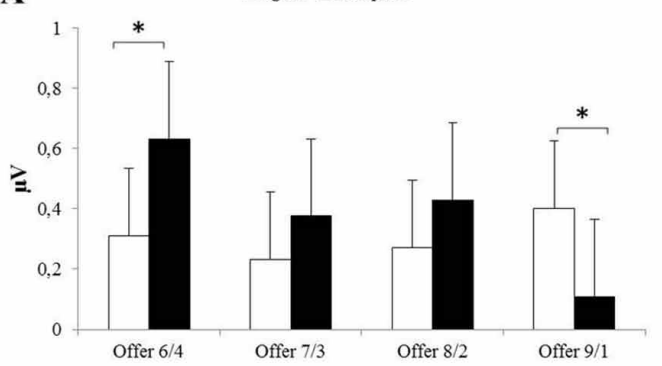

Presentation of the offer: Levator Labii

B

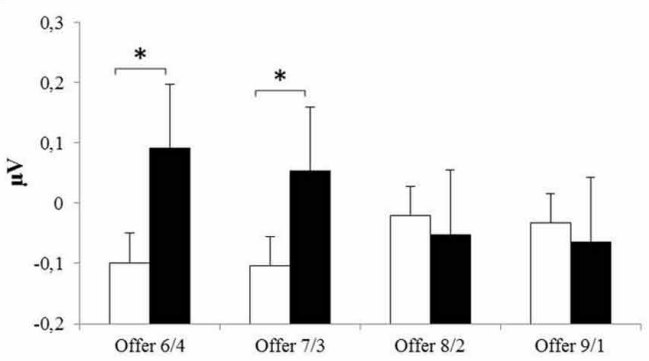

Presentation of the offer: Zygomaticus Major

C

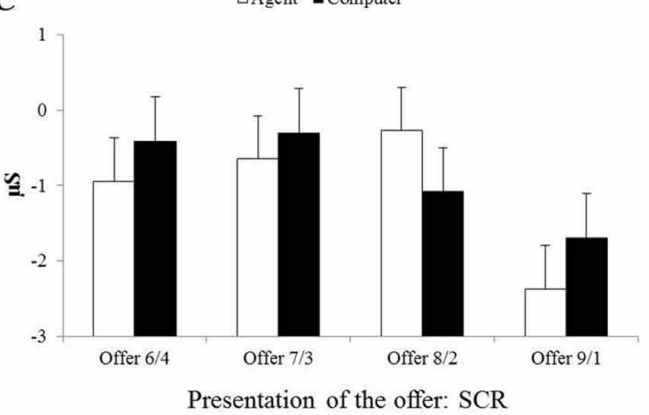

$\square$ Agent $\square$ Computer

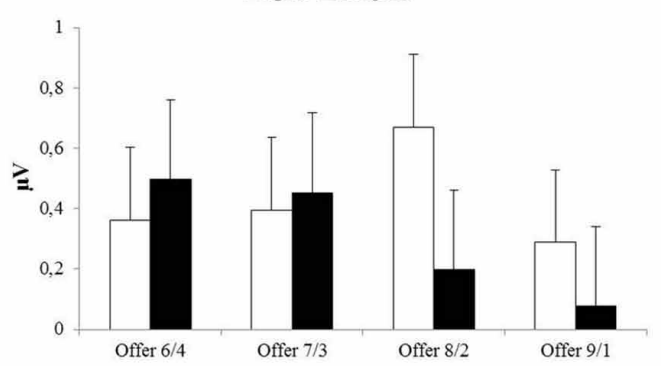

Response to the offer: Levator Labii

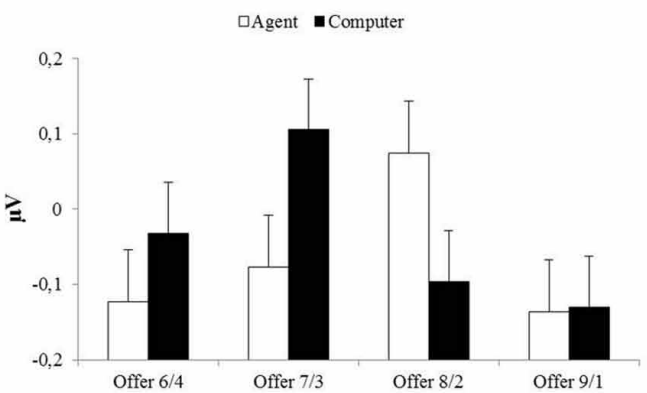

Response to the offer: Zygomaticus Major

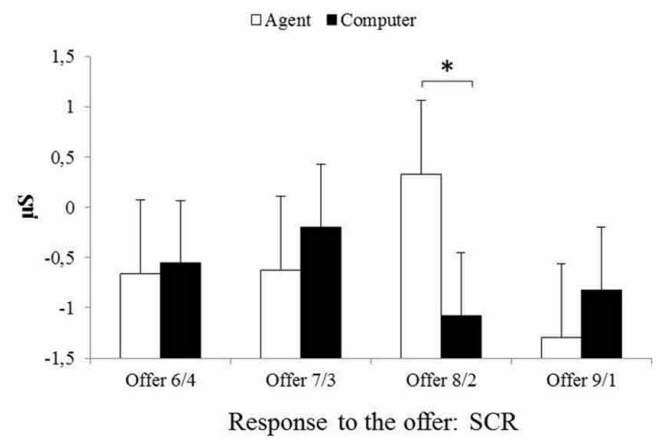

\section{EXPERIMENT 2}

The purpose of this experiment was to explore the impact of group membership on participants' decisions in the ultimatum game, played with computer agents that embodied ethnic out-group and regular computers.

\section{Method}

Participants. 21 students (9 men), ranging in age from 18 to 22 years $(M=19.90, S D=1.18)$, at Jacobs University Bremen, Germany, participated in the experiment on a voluntary basis. They were recruited via e-mail and received $10 \%$ of the amount earned in the ultimatum game and a course credit as compensation. All participants were Caucasian and fluent in English. 
Materials. Images of the proposers included 10 faces of South Asian (Indian) males obtained from the Center for Vital Longevity Face Database (Minear \& Park, 2004) and one photograph of a laboratory computer. As in Experiment 1, the faces were modified in Photoshop (CS3-ME, Adobe Systems Inc., 2007) in order to make them appear artificial. The images of South Asian faces and of the laboratory computer (same as in Experiment 1) measured 473 x 586 pixels and were displayed vertically on a black screen.

Procedure. The procedure closely followed that employed in Experiment 1 in the setup of the game played with computer agents and a single regular computer. Participants were to either accept or reject offers coming in 10 trials from agents, represented by images of 10 different South Asian faces, and in another 10 trials, from a computer, represented by a picture of a laboratory computer. The offers were the same as in Experiment 1. Physiological activity was not recorded.

\section{Results}

Percentages of accepted offers in the current experiment are displayed in Figure 5. A repeatedmeasures ANOVA was conducted with Proposer (Agents, Single Computer) and Offer (5/5, 6/4, 7/3, $8 / 2,9 / 1)$ as the two within-subjects factors. The main effects were significant, both for Proposer, $F(1$, $20)=6.99, p=.016, \eta_{p}^{2}=.26$, and Offer, $F(4,17)=25.23, p<.001, \eta_{p}{ }^{2}=.86$. These main effects were qualified by a significant interaction, $F(4,17)=4.42, p=.012, \eta_{p}^{2}=.51$. Overall, participants accepted Offers $7 / 3$ and $9 / 1$ more often when they came from a regular computer $\left(M_{7 / 3}=.65\right.$ and $\left.M_{9 / 1}=.29\right)$ than from computer agents $\left(M_{7 / 3}=.51\right.$ and $\left.M_{9 / 1}=.10 ; p s<.05\right)$.

Data from Experiment 2 were compared with those from Experiment 1 (version with a single computer) to test for the effect of the agents' Ethnicity (Caucasian, South Asian) on participants' decisions. A repeated-measures ANOVA with Offer as within-subjects factor and Ethnicity as betweensubjects factor showed that the main effect of Ethnicity was not significant $(p>.05)$.

\section{Discussion}

The behavioral results adhered to the pattern obtained in Experiment 1 in that the unjust splits were accepted less often when proposed by the agents compared to the regular computer. Contrary to the hypothesis, ethnicity of the agents did not induce definitive changes in participants' decisions in the game.

\section{CONCLUSION}

Prior research has found people to consistently arrive at different decisions with regard to the same monetary incentives offered by another human compared to a computer. The latter are more likely to be accepted even when they are unfair. The present research focused on the investigation of the behavioral and emotional components of reactions to computers in the context of the ultimatum game. Unlike in the earlier studies, participants' choices were not contrasted with their reactions to human partners. By avoiding the potential confound of an interaction with both another human and an object, the magnitude of social responses to computers was explored. On the behavioral level, in Experiments 1 and 2 almost all fair and the least unfair splits were accepted. As expected, the acceptance rates declined as the splits became more unequal and they varied as a function of the partner's anthropomorphic appearance. Unfair offers from non-anthropomorphic, regular computer were accepted more often than the offers from highly anthropomorphic computer agents. In general, both types of computers' representations elicited social responses analogous to responses to humans in that participants seemed to have perceived the unjust behaviors in terms of a transgression, for which the computer deserved a symbolic punishment. This phenomenon was stronger for the computers represented by facial images.

In Experiment 1, participants' physiological responses did not fluctuate consistently depending on the type of the proposer in the game or the presented offer. Lack of evidence for the expected 


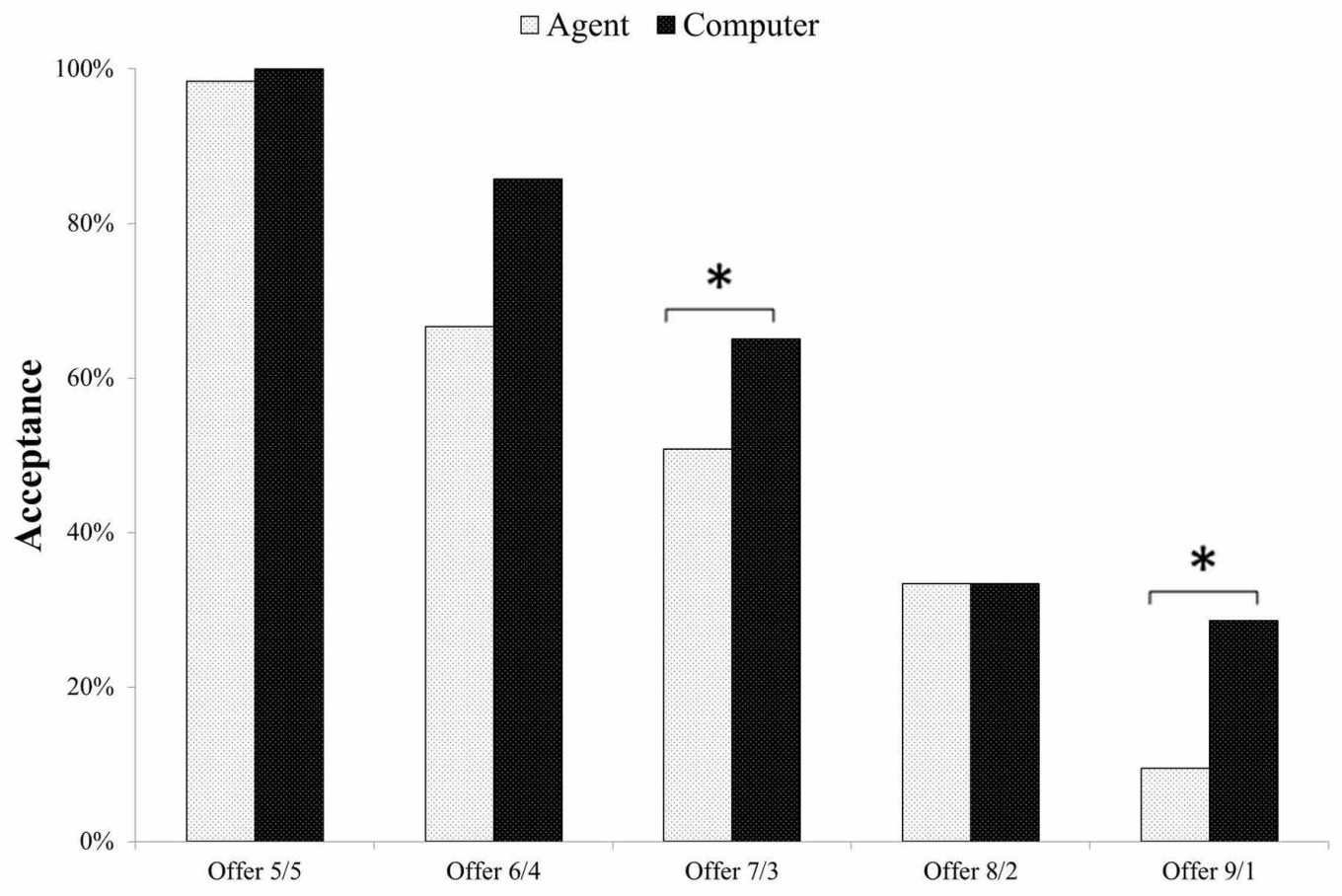

emotional reactions to the unfairness of the computer indicates that its role as a social partner was limited to how it shaped the relevant behaviors. Further demonstration of the diminished social function of the computer was the absence of the predicted influence of the computer agents that embodied an ethnic out-group to participants in Experiment 2. The ethnicity of the computer, similarly symbolized by faces, has been previously shown to have a strong effect on participants in the human-computer interaction, just like an actual human in a human-human interaction. However, this concerned a slightly different evaluation task that did not directly affect participants' own outcomes (Nass \& Moon, 2000). Although the proposition of an inequitable split in the ultimatum game was an instance of a violation of social norms, tangible in terms of financial losses, and people are typically more receptive of transgressions by out-group members (Valdesolo \& DeSteno, 2007), reactions to the out-group computer agents appeared not to be clearly more negative than to the in-group agents.

These results may be interpreted in support of the ethopoeia approach. Ethopoeia puts an emphasis on the mindless execution of familiar behavioral scripts, attributed in turn to automatic cognitive processing that does not reach conscious awareness. It argues that even minimal social cues provided by a computer are sufficient for it to temporarily become a fellow human and the virtual world to become real to participants (Reeves \& Nass, 1996). The more human-like characteristics the computer manifests, the more pronounced its social impact is (Nass \& Moon, 2000). Nonetheless, the realization of behavioral scripts alone cannot fully explain decisions to reject concrete offers in the ultimatum game. These derive from negative emotions (e.g., anger, as well as wounded pride and spite; Straub \& Murnighan, 1995). In the current setting, the emotional reactions might have been too subtle to capture.

Although human game partners were excluded from the interaction, with the focus of the present research on the interaction with objects, inclusion of highly realistic artificial faces to represent a proposer still constituted a stark contrast to a regular computer as proposer. Future studies could 
address this issue by improving the stimulus material. For example, the faces may be shown together with a background as part of an interface displayed on a monitor to reinforce the idea that they are computer-based entities. In addition, the faces could be animated to display emotional expressions dependent on participants' responses (de Melo et al., 2013). This would serve as another strong social cue more likely to elicit emotional responses, which were very limited in the present context. Moreover, the computer's subsequent offers could be contingent on participants' decisions (e.g., increasing when preceded by a rejection of a low offer). The computer could also take on the role of the responder with participants acting as proposers (Nouri \& Traum, 2013). If participants would offer the computer fair or almost fair monetary splits, this would be evidence for a social interaction with an object coming about.

The advancement of ethopoeia approaches and the research it inspired have reflected a steady improvement in the quality of HCI, partly because regular computers with text or audio output evolved into machines that incorporate anthropomorphic interfaces (Reeves \& Nass, 1996). The Threshold Model of Social Influence contributed to better understanding of interactions with avatars and agents (e.g., Von der Pütten, Krämer, Gratch, \& Kang, 2010). An essential commonality of the two approaches is that they seek to elucidate the interplay of people and a variety of computer-generated entities. In doing so, they tend to center on human-like appearance and behavior, which augment social cues and are seen as advantageous for HCI by making it more natural and intuitive, and akin to HHI (Breazeal, 2002). While the computers began to fulfill roles once reserved for humans (Küster, Krumhuber, \& Kappas, 2014), the range of the users' responses expanded from mainly task-oriented to emotional engagement. Some applications (e.g., educational programs) actually require the user to be emotionally involved for the intervention to be successful. Moreover, emotions are associated with reactions to moral violations, as in the ultimatum game, and this opens up the possibility for the computer to become a partner with moral obligations. Taken together, it seems that ethopoeia and the Threshold Model of Social Influence may not cover all of the intricacies of the HCI.

\section{ACKNOWLEDGMENT}

This research was supported by a grant from the EU FP7 project eCUTE (ICT-5-4.2 257666) to Arvid Kappas. Correspondence concerning this article should be addressed to Aleksandra Swiderska, Department of Psychology, Warsaw University, ul. Stawki 5/7, 00-183 Warsaw, Poland. E-mail: aleksandra.swiderska@psych.uw.edu.pl, Tel.: +48 225549 811, Fax: +48 226357991. 


\section{REFERENCES}

Becker, G. S. (2013). The economic approach to human behavior. Chicago, IL: University of Chicago Press.

Blascovich, J., Loomis, J., Beall, A. C., Swinth, K. R., Hoyt, C. L., \& Bailenson, J. N. (2002). Immersive virtual environment technology as a methodological tool for social psychology. Psychological Inquiry, 13(2), 103-124. doi:10.1207/S15327965PLI1302_01

Boucsein, W., Fowles, D. C., Grimnes, S., Ben-Shakhar, G., Roth, W. T., Dawson, M. E., \& Filion, D. L. (2012). Publication recommendations for electrodermal measurements. Psychophysiology, 49(8), 1017-1034. doi:10.1111/j.1469-8986.2012.01384.x PMID:22680988

Bradley, M. M., Lang, P. J., \& Cuthbert, B. N. (1993). Emotion, novelty, and the startle reflex: Habituation in humans. Behavioral Neuroscience, 107(6), 970-980. doi:10.1037/0735-7044.107.6.970 PMID:8136072

Breazeal, C. L. (2002). Designing sociable robots. Cambridge, MA: MIT Press.

Cannon, P. R., Schnall, S., \& White, M. (2011). Transgressions and expressions: Affective facial muscle activity predicts moral judgments. Social Psychological \& Personality Science, 2(3), 325-331. doi:10.1177/1948550610390525

Chapman, H. A., Kim, D. A., Susskind, J. M., \& Anderson, A. K. (2009). In bad taste: Evidence for the oral origins for moral disgust. Science, 27(5918), 1222-1226. doi:10.1126/science.1165565 PMID:19251631

de Melo, C., Gratch, J., \& Carnevale, P. (2013). The effect of agency on the impact of emotion expressions on people's decision making. In Proceedings of the 5th Humaine Association Conference on Affective Computing and Intelligent Interaction (ACII) (pp. 546-551). doi:10.1109/ACII.2013.96

Fehr, E., \& Gächter, S. (2002). Altruistic punishment in humans. Nature, 415(6868), 137-140. doi:10.1038/415137a PMID:11805825

Fridlund, A. J., \& Cacioppo, J. T. (1986). Guidelines for human electromyographic research. Psychophysiology, 23(5), 567-589. doi:10.1111/j.1469-8986.1986.tb00676.x PMID:3809364

Krumhuber, E., Tsankova, E., \& Kappas, A. (2016). Examining subjective and physiological responses to norm violation using text-based vignettes. International Journal of Psychology. doi:10.1002/ijop.12253 PMID:26762218

Krumhuber, E. G., Swiderska, A., Tsankova, E., Kamble, S. V., \& Kappas, A. (2015). Real or artificial? Intergroup biases in mind perception in a cross-cultural perspective. PLoS One, 10(9), e0137840. doi:10.1371/ journal.pone.0137840 PMID:26360588

Kubota, J. T., Li, J., Bar-David, E., Banaji, M. R., \& Phelps, E. A. (2013). The price of racial bias: Intergroup negotiations in the Ultimatum Game. Psychological Science, 24(12), 2498-2504. doi:10.1177/0956797613496435 PMID:24121413

Küster, D., Krumhuber, E., \& Kappas, A. (2014). Nonverbal behavior online: A focus on interactions with and via artificial agents and avatars. In A. Kostic \& D. Chadee (Eds.), Social Psychology of Nonverbal Communications (pp. 272-302). New York, NY: Palgrave Macmillan.

Minear, M., \& Park, D. C. (2004). A lifespan database of adult facial stimuli. Behavior Research Methods, Instruments, \& Computers, 36(4), 630-633. doi:10.3758/BF03206543 PMID:15641408

Mullen, B., Brown, R., \& Smith, C. (1992). Ingroup bias as a function of salience, relevance, and status: An integration. European Journal of Social Psychology, 22(2), 103-122. doi:10.1002/ejsp.2420220202

Nass, C., \& Moon, Y. (2000). Machines and mindlessness: Social responses to computers. The Journal of Social Issues, 56(1), 81-103. doi:10.1111/0022-4537.00153

Nass, C., Moon, Y., \& Carney, P. (1999). Are respondents polite to computers? Social desirability and direct responses to computers. Journal of Applied Social Psychology, 29, 1093-1110. doi:10.1111/j.1559-1816.1999. tb00142.x

Nass, C., Moon, Y., \& Green, N. (1997). Are computers gender-neutral? Social desirability and direct responses to computers. Journal of Applied Social Psychology, 27, 864-876. doi:10.1111/j.1559-1816.1997.tb00275.x 
Nouri, E., \& Traum, D. (2013). A cross-cultural study of playing simple economic games online with humans and virtual humans. In M. Kurosu (Ed.), Human-Computer Interaction. Applications and Services. HCI 2013, LNCS (Vol. 8005, pp. 266-275). Berlin, Germany: Springer. doi:10.1007/978-3-642-39262-7_30

Nowak, M. A., Page, K. M., \& Sigmund, K. (2000). Fairness versus reason in the Ultimatum Game. Science, 289(5485), 1773-1775. doi:10.1126/science.289.5485.1773 PMID:10976075

Reeves, B., \& Nass, C. (1996). The media equation: How people treat computers, television, and new media like real people and places. New York, NY: Cambridge University Press.

Sanfey, A. G., Rilling, J. K., Aronson, J. A., Nystrom, L. E., \& Cohen, J. D. (2003). The neural basis of economic decision-making in the Ultimatum Game. Science, 300(5626), 1755-1758. doi:10.1126/science.1082976 PMID:12805551

Straub, P., \& Murnighan, J. K. (1995). An experimental investigation of ultimatum games: Information, fairness, expectations, and lowest acceptable offers. Journal of Economic Behavior \& Organization, 27(3), 345-364. doi:10.1016/0167-2681(94)00072-M

Tinwell, A., Grimshaw, M., Nabi, D. A., \& Williams, A. (2011). Facial expression of emotion and perception of the Uncanny Valley in virtual characters. Computers in Human Behavior, 27(2), 741-749. doi:10.1016/j. chb.2010.10.018

Valdesolo, P., \& DeSteno, D. (2007). Moral hypocrisy: Social groups and the flexibility of virtue. Psychological Science, 18(8), 689-690. doi:10.1111/j.1467-9280.2007.01961.x PMID:17680939

van't Wout, M., Kahn, R. S., Sanfey, A. G., \& Aleman, A. (2006). Affective state and decision making in the Ultimatum Game. Experimental Brain Research, 169(4), 564-568. doi:10.1007/s00221-006-0346-5 PMID:16489438

Von der Pütten, A. M., Krämer, N. C., Gratch, J., \& Kang, S. H. (2010). "It doesn't matter what you are!": Explaining social effects of agents and avatars. Computers in Human Behavior, 26(6), 1641-1650. doi:10.1016/j. chb.2010.06.012

Waytz, A., Epley, N., \& Cacioppo, J. T. (2010). Social cognition unbound: Insights into anthropomorphism and dehumanization. Current Directions in Psychological Science, 19(1), 58-62. doi:10.1177/0963721409359302 PMID:24839358

Yee, N., Bailenson, J. N., \& Rickertsen, K. (2007). A meta-analysis of the impact of the inclusion and realism of human-like faces on user experiences in interfaces. In Proceedings of the SIGCHI conference on human factors in computing systems. New York, NY: ACM. doi:10.1145/1240624.1240626

\begin{abstract}
Aleksandra Swiderska is currently a research associate at the Department of Psychology at Warsaw University, Poland. She received her PhD degree in Psychology from Jacobs University Bremen, Germany, in 2015, and later was a post-doc at the Center for Research on Prejudice at Warsaw University until 2017. Her main research interests fall at the intersection of social cognition, emotion psychology, and psychophysiology, and in particular focus on the processes of dehumanization and anthropomorphism, especially the perceptions of and emotional reactions to artificial characters and robots in socio-moral interactions.
\end{abstract}

Eva Krumhuber is an assistant professor in Experimental Psychology at University College London, United Kingdom. She obtained her doctoral degree in social psychology from Cardiff University in 2008 and has been a member of the editorial board of the Journal of Nonverbal Behavior since 2010. Her research focuses on the expression and perception of emotions in the human face. Besides her scientific contributions to psychology, her research has proved relevant for the successful modelling of emotions in virtual characters, being commercially used by the film and video games industries.

Arvid Kappas is professor of psychology and dean at Jacobs University Bremen. He has been conducting research on emotions for over 25 years. Having obtained his PhD at Dartmouth College, NH, USA, he has lived and worked in Switzerland, Canada, the UK, and in Germany. He was also visiting professor in Austria and in Italy. He is a fellow of the Association for Psychological Science and the Society for Personality and Social Psychology and from 2013-2018 president of the International Society for Research on Emotion. His interests include affective computing and social robotics. 